LBL --30318

DE92 000854

\title{
VERS.ATILE HIGH CURRENT METAL ION IMPLANTATION FACILITY
}

I. G. Brown, M. R. Dickinson, J. E. Galvin, X. Godechot* and R. A. MacGill

Lawrence Berkeley Laboratory

University of California

Berkeley, CA 94720

Presented at the

7th International Conference on

Surface Modification of Metals by Ion Beams

Washington, D.C.

July $15-19,1991$

June 1991

* On leave to Lawrence Berkeley Laboratory from SODERN. Present address SODERN, 1 Ave. Descartes, 94451 Limeil-Brevannes, France. Supported by a Grant from the French Ministère des Affaires Etrangère, Bourse Lavoisier, and a Grant from SODERN.

This work was supported by the U.S. Army Research Office under Contract No. ARO 105-91, the Office of Naval Research under Contract No. N00014-88-F-0093, and through the Department of Energy under Contract No. DE-AC03-76SF00098. 


\title{
VERSATILE HIGH CURRENT METAL ION IMPLANTATION FACILITY
}

\author{
I. G. Brown, M. R. Dickinson, J. E. Galvin, X. Godechot and R. A. MacGill
}

\author{
Lawrence Berkeley Laboratory \\ University of California \\ Berkeley, CA 94720
}

\begin{abstract}
$\underline{\text { ABSTRACT }}$
A metal ion implantation facility has been developed with which high current beams of practically all the solid metals of the periodic table can be produced. A multi-cathode, broad beam, metal vapor vacuum arc ion source is used to produce repetitively pulsed metal ion beams at an extraction voltage of up to $100 \mathrm{kV}$, corresponding to an ion energy of up to several hundred keV because of the ion-charge state multiplicity, and with a beam current of up to several amperes peak pulsed and several tens of $\mathrm{mA}$ time averaged delivered onto a downstream target. Implantation is done in a broad-beam mode, with a direct line-of-sight from ion source to target. Here we summarize some of the features of the ion source and the implantation facility that has been built up around it.
\end{abstract}




\section{INTRODUCTION}

A program to develop the Mevva (metal vapor vacuum arc) high current metal ion source was undertaken at LBL commencing in 1982, initially for the production of high current uranium ion beams for fundamental heavy ion nuclear physics research [1,2] and more recently for metallurgical and special purpose ion implantation applications. Several different versions of source have been generated and used for these purposes at LBL [3-8] and similar sources have also been made elsewhere around the world [9-12]. The most recent LBL, version, Mevva V [8], is a multi-cathode, broad beam, source embodiment. It has been incorporated into a test-stand which has been adapted for flexibility and convenience in carrying out a wide range of experimental implantations.

The source is operated in a repetitively pulsed mode with pulse width $0.25 \mathrm{~ms}$ and repetition rate several tens of pulses per second. Ion beam current actually delivered onto target can be over 1 ampere peak or several tens of $\mathrm{mA}$ time-averaged. Beam extraction voltage can be up to $100 \mathrm{kV}$, and since the ions generated by the vacuum arc are in general multiply ionized with a charge state distribution with a mean between 1 and 3 and with components up to 5 or 6 , the mean ion beam energy can be up to about $300 \mathrm{keV}$ and with components over $500 \mathrm{keV}$. We have operated with a very wide range of metallic elements, including $\mathrm{Li}, \mathrm{C}, \mathrm{Mg}, \mathrm{Al}, \mathrm{Si}, \mathrm{Ca}, \mathrm{Sc}, \mathrm{Ti}, \mathrm{V}$, $\mathrm{Cu}, \mathrm{Mn}, \mathrm{Fe}, \mathrm{Co}, \mathrm{Ni}, \mathrm{Cu}, \mathrm{Zn}, \mathrm{Ge}, \mathrm{Sr}, \mathrm{Y}, \mathrm{Zr}, \mathrm{Nb}, \mathrm{Mo}, \mathrm{Pd}, \mathrm{Ag}, \mathrm{Cd}, \mathrm{In}, \mathrm{Sn}, \mathrm{Ba}, \mathrm{La}, \mathrm{Cc}, \mathrm{Pr}, \mathrm{Nd}$, $\mathrm{Sm}, \mathrm{Gd}, \mathrm{Dy}, \mathrm{Ho}, \mathrm{Er}, \mathrm{Tm}, \mathrm{Yb}, \mathrm{Hf}, \mathrm{Ta}, \mathrm{W}, \mathrm{Ir}, \mathrm{Pt}, \mathrm{Au}, \mathrm{Pb}, \mathrm{Bi}, \mathrm{Th}$ and $\mathrm{U}$. The multi-cathode assembly can hold 18 separate cathodes at one time, and the beam species can be changed simply and quickly.

The implanter is uncomplicated and operates reliably. We have used it for carrying out a wide range of research implantations into metals, semiconductors, ceramics and high- $\mathrm{T}_{\mathrm{c}}$ superconductors. Doses of up to $1 \times 10^{18} \mathrm{~cm}^{-2}$ have been produced in targets of area up to 100 $\mathrm{cm}^{2}$. The target can be kept at low temperature or can be heated to incandescence by the beam itself, according to the experimental requirements. Overlapping implantations of several metallic species can readily be done.

\section{DESCRIPTION OF THE IMPLANTER}

The heart of the implanter is a Mevva ion source. In this kind of source a metal vapor 
vacuum arc is used as the means for generating the plasma medium from which an energetic ion beam is formed, and the distinguishing feature of the source is the very high beam current of metal ions that can be produced. We have constructed several different Mevva sources for different applications, and the design and performance characteristics have been described [3-8]. The source is operated in a pulsed mode with a pulse length typically in the range $0.1-5 \mathrm{msec}$ and a repetition rate of up to about 100 pps depending on the mean power dissipation.

The implantation facility uses a Mevva V source [8]. This source version is a multi-cathode design in which a circular cathode assembly houses an array of 18 separate cathodes which can be rotated so as to position any one of them into the firing position rapidly and while under high vacuum. The operational lifetime (time for which the source can operate continuously before it is necessary to replace the cathodes) is thus increased by a factor of 18 , or alternatively, different cathode materials can be installed and the beam species switched simply and swiftly. The ability to switch between different metal species provides a valuable operational feature and makes possible a range of experiments that would otherwise be difficult or impossible. The extractor diameter is 10 $\mathrm{cm}$. A photograph of the partially-disassembled source showing the multicathode feature and the large area extractor is shown in Figure 1.

Implantation is done in a broad-beam mode, without magnetic analysis of the beam components, and the ion trajectories are line-of-sight from ion source to target. The high ion charge density demands a very high degree of space charge neutralization of the beam, and any attempt at magnetic analysis would cause a major perturbatio, to the neutralizing electrons and consequent space charge blow-up and loss of beam. However, the Mevva ion beam is particularly pure, containing a high fraction of just the wanted metal ion species; this is because the plasma is formed solely from the cathode material where the cathode spots of the vacuum arc are active, and there is no carrier gas. Thus implantation in a non-mass-analyzed mode is satisfactory for many purposes (but not all).

The ion beam charge state distribution can be measured using a time-of-flight diagnostic that forms an appendage to the main chamber. A Faraday cup detector measures the current in the different $\mathrm{Q} / \mathrm{A}$ states and provides a good measurement of the composition of the extracted ion beam. The time-of-flight system has been described in more detail elsewhere [13].

The vacuum chamber is cryogenically pumped and the pressure during implantation is typically in the low-to-mid $10^{-6}$ Torr range. The target is introduced into the vessel through an air 
lock and the time required for target changes can be as short as a matter of minutes. The target is mounted on a water-cooled holder suspended from a vertically moving shaft; the source-to-target distance is $65 \mathrm{~cm}$. A magnetically-suppressed Faraday cup with a $5 \mathrm{~cm}$ diameter entrance aperture can be inserted into the beam immediately in front of the target and the beam current can thus be adjusted to accumulate the required implantation dose. The overall set-up is shown in Figure 2.

\section{PERFORMANCE CHARACTERISTICS}

An example of the implanter beam current performance for the case of a titanium beam is shown in Figure 3. Here the pulse current density delivered to the magnetically-suppressed Faraday cup immediately in front of the target is plotted as a function of extraction voltage for a range of different arc currents. For this particular case the peak ion beam current density was up to $20 \mathrm{~mA} / \mathrm{cm}^{2}$ and the time-averaged current density approximately $1 \%$ of this.

In typical operation beam is formed at $50-75 \mathrm{kV}$ ion source extraction voltage, and the maximum voltage at which we have operated is $110 \mathrm{kV}$. Depending on the charge state spectrum of the ion species used, the mean energy of the ions can be $200-300 \mathrm{keV}$ with components as high as $500 \mathrm{keV}$. Beam can be formed from practically any electrically conducting cathode material. We have tested and used nearly 50 of the solid metals of the periodic table, listed above. Compound and alloy cathode materials have also been investigated and mixed-composition beams can be produced. The ion charge state spectra have been studied in detail [14-16]. An oscillogram of the charge state spectrum for an Ir ion beam is shown in Figure 4.

Cathode lifetime is limited by cathode erosion and is typically in the range $10^{5}-10^{6}$ pulses depending on the arc current and pulse length; thereafter triggering becomes erratic and difficult. Since there are 18 cathodes in a single Mevva V cathode assembly, the source can be operated steadily for many days before it is necessary to vent the source to atmospheric to replace the cathodes. Soft materials like $\mathrm{Li}, \mathrm{Sn}$ and $\mathrm{Pb}$ tend to have a shorter lifetime due to plating over of the cathode/trigger insulator, but this depends on the arc current.

The maximum duty cycle at which the source can be operated is determined by several factors, principally the limitation set by the electronics, including the trigger generator, arc supply and extractor supply; heat removal from the arc region is also a concern. Our electronics limits us at present to about $1 \%$. 


\section{APPLICATIONS}

The high dose that can be accumulated in a short time over a relatively large substrate area makes the Mevva ion implantation technology well suited to metallurgical surface modification applications, where it is usual that the abundance of inexpensive ions in very large quantities is a primary concern. Also, although the Mevva ion beam characteristics make the source not ideal as a simple retrofit to traditional semiconductor implanters, the implanter can be a valuable tool for specialized or unusual implants into semiconductors, especially in a research mode. We have used the facility for exploratory research in a variety of different ion implantation applications, including semiconductor, superconductor, ceramics and metallurgical applications. These research projects include: high temperature oxidation inhibition of metal surfaces by implantation of reactive elements [17]; inhibition of aqueous corrosion of iron and steel by metal ion implantation [18]; hardening of ceramic and steel surfaces by high dose implantation; Ir implantation into Si for buried conducting $\mathrm{IrSi}_{3}$ layer synthesis [19]; high dose $\mathrm{U}$ implantation into Si [20]; formation of buried strained $\mathrm{Si}_{1-\mathrm{x}} \mathrm{Ge}_{\mathrm{x}}$ layers in $\mathrm{Si}$; implantation of $\mathrm{U}$ into $\mathrm{GaAs}$ and $\mathrm{InP}$ for fluorescence studies [21]; implantation of $\mathrm{Ti}, \mathrm{Pd}$, and $\mathrm{W}$ into $\mathrm{Si}$ for selective $\mathrm{CVD}$ seeding [22]; $\mathrm{Y}$ and $\mathrm{Cu}$ ion implantation into $\mathrm{YBCO}$ for high- $\mathrm{T}_{\mathrm{c}}$ superconducting thin film compositional 'fine tuning' [23]; and a fundamental study of ion ranges in carbon [24].

\section{FUTURE DEVELOPMENT}

As a laboratory research tool the Mevva technology works well in its present state of development for a wide range of applications, as illustrated by the scope of the implantations mentioned above. The range of metal ion species, the high beam current that can be delivered onto target, the large cross-sectional area of the beam, and source features such as simplicity and the multi-cathode design, all add together to provide an adaptable and practical research tool.

The intense plume of metal plasma that is generated at the micron-sized cathode spots on the cathode surface is accompanied by a component of micron-size solid droplets ("macroparticles") [25,26], and for some applications this could be a disadvantage. Macroparticle generation is less for higher melting point cathode materials, and there is a serendipitous natural separation mechanism in that the unwanted macroparticle flux is mostly in a direction close to parallel to the cathode surface. It should be possible to completely remove the macroparticle fraction from the plasma stream by incorporating a magnetic filter [27,28] within the plasma region

$$
-5
$$


of the ion source. We have carried out some studies of plasma ducting and macroparticle filtering [28], and more work remains to be done.

The low duty cycle pulsed operation of the source described here is not an inherent limiting characteristic, but is simply a legacy from its synchrotron-based lineage. We are presently developing a de version capable of delivering amperes of metal ion beam current. Because of the high dc beam power densities that then occur, both at the beam formation electrodes and at the target, it becomes natural to consider very large size beam dimensions, and for these as well as other reasons our dc source development incorporates the dual features of dc vacuum arc plasma generator and very large area extractor grids. Our first dc tests were limited in voltage by the power supplies that were conveniently available to us. At a low extraction voltage of just $9 \mathrm{kV}$ (about $18 \mathrm{keV}$ mean ion energy, by virtue of the ion charge state distribution) and using an $18-\mathrm{cm}$ diameter set of multi-aperture extraction grids, a dc titanium ion beam current of approximately 0.6 amperes was measured. Separately, we have tested and formed beam from a $50 \mathrm{~cm}$ diameter $\left(2000 \mathrm{~cm}^{2}\right)$ set of extractor grids using a pulsed plasma gun. This configuration appears to be particularly efficient in terms of plasma utilization, and we have formed beams with ion current up to 7 amperes at an extraction voltage of $50 \mathrm{kV}$ (about $100 \mathrm{keV}$ ) and up to 20 amperes peak (at the current overshoot part of the beam pulse). A photograph of the $50 \mathrm{~cm}$ extractor is shown in Figure 5. The dc implantation facility will combine a dc plasma gun and a very-large-area extractor of this kind.

\section{CONCLUSION}

The implantation facility described here, based on the metai vapor vacuum arc ion source, provides a unique tool for carrying out metal ion implantation experiments. Energetic, high current, large area beams of a wide range of metallic ion species can be produced and delivered onto target. Both the ion source and the rudimentary implanter are simple, inexpensive, and flexible. Present embodiments operate in a repetitively pulsed mode and provide a time-averaged ion beam current of up to some tens of milliamperes onto a downstream target, and a very broad beam, dc facility capable of producing ampere beams is under development. 


\section{ACKNOWLEDGEMENTS}

This work was supported by the U.S. Army Research Office and the Office of Naval Research under Contract No. ARO 116-89 and by the Department of Energy under Contract No. DE-AC0376 SF00098.

*Present address: Sodern, 1 Ave. Descartes, 94451 Limeil-Brevannes, France; supported at LBL by a grant from the French Ministère des Affaires Etrangères, Bourse Lavoisier, and a grant from Sodern. 


\section{REFERENCES}

1. J. Alonso, Nucl. Instrum. Methods A244 (1986) 262.

2. B. Feinberg and I. G. Brown, Proc. 1987 Particle Accelerator Conf, Washington DC, March 1987, (IEEE, Cat. No. 87CH2387-9), p. 860.

3. I. G. Brown, J. E. Galvin and R. A. MacGill, Appl. Phys. Lett. 47 (1985) 358.

4. I. G. Brown, J. E. Galvin, B. F. Gavin and R. A. MacGill, Rev. Sci. Instrum. 57 (1986) 1069.

5. I. G. Brown, J. E. Galvin, R. A. MacGill and R. T. Wright, Appl. Phys. Lett. 49 (1986) 1019.

6. R A. MacGill, I. G. Brown and J. E. Galvin, Rev. Sci. Instrum. 61 (1990) 580.

7. I. G. Brown, in "The Physics and Technology of Ion Sources", edited by I. G. Brown (Wiley, New York, 1989), p. 331.

8. I. G. Brown, J. E. Galvin, R. A. MacGill and F. J. Paoloni, Rev. Sci. Instrum. 61 (1990) 577.

9. S. Humphries, Jr., C. Burkhart, S. Coffey, G. Cooper, L. K. Len, M. Savage, D. M. Woodall, H. Rutkowski, H. Oona and R. Shurter, J. Appl. Phys. 59 (1986) 1790.

10. P. Spaedtke, H. Emig, J. Klabunde, D. M. Rueck, B. H. Wolf and I. G. Brown, Nucl. Instrum. and Methods A278, (1989) 643.

11. H. Zhang, Z. Zhang, F. Zhou, S. Zhang and Z. Han, Rev. Sci. Instrum. 61 (1990) 574.

12. A. I. Ryabchikov, Rev. Sci. Instrum. 61 (1990) 641.

13. I. G. Brown, J. E. Galvin, R. A. MacGill and R. T. Wright, Rev. Sci. Instrum. 58 (1987) 1589.

14. I. G. Brown, B. Feinberg and J. E. Galvin, J. Appl. Phys. 63 (1988) 4889.

15. I. G. Brown and X. Godechot, "Vacuum Arc Ion Charge State Distributions", 14th International Symposium on Discharges and Electrical Insulation in Vacuum, Santa Fe, NM, September 16-20,1990; to be published in IEEE Trans. Plasma Sci. (1991).

16. J. Sasaki and I. G. Brown, J. Appl. Phys. 66 (1989) 5198.

17. P. Hou, I. G. Brown and J. Stringer, 7th International Conference on Ion Beam Modification of Materials, Knoxville, TN, September 9-14, 1990.

18. W. Tian, R. Wu, R. Wang, X. Godechot and I. G. Brown, papers presented at this conference.

19. K. M. Yu, B. Katz, I. C. Wu and I. G. Brown, Mat. Res. Soc. Symp. Proc. 147 (1989) 229.

20. I. G. Brown, J. E. Galvin and K M. Yu, Nucl. Instrum. Methods B31 (1988) 558. 
21. G. S. Pomrenke, R. L. Hengehold, Y. K. Yeo, I. G. Brown and J. S. Solomon, J. Appl. Phys. 67 (1990) 2040.

22. X. Y. Qian, M. H. Kiang, N. W. Cheung, M. A. Lieberman, I. G. Brown, X. Godechot and $\mathrm{K}$ M. Yu, 8th International Conference on Ion Implantation Technology, Guildford, U.K., July, 1990.

23. M. Rubin, I. G. Brown, E. Yin and D. Wruck, J. Appl. Phys. 66 (1989) 3940.

24. G. Dearnaley, J. L. Ing, I. G. Brown and X. Godechot, "Anomalous Ranges of Ions Implanted into Carbon", paper presented at this conference.

25. J. E. Daalder, Physica 104C, (1981) 91.

26. I. I. Aksenov, I. I. Konovalov, E. E. Kudryavtseva, V. V. Kunchenko, V. G. Padalka and V. M. Khoroshikh, Sov. Phys. Tech. Phys. 29(8), (1984) 893.

27. V. S. Voitsenya, A. G. Gorbanyuk, I. N. Onishchenko and B. G. Safranov, Sov. Phys. Tech. Phys. 9(2), (1964) 221.

28. J. Storer, J. E. Galvin and I. G. Brown, J. Appl. Phys. 66, (1989) 5245. 


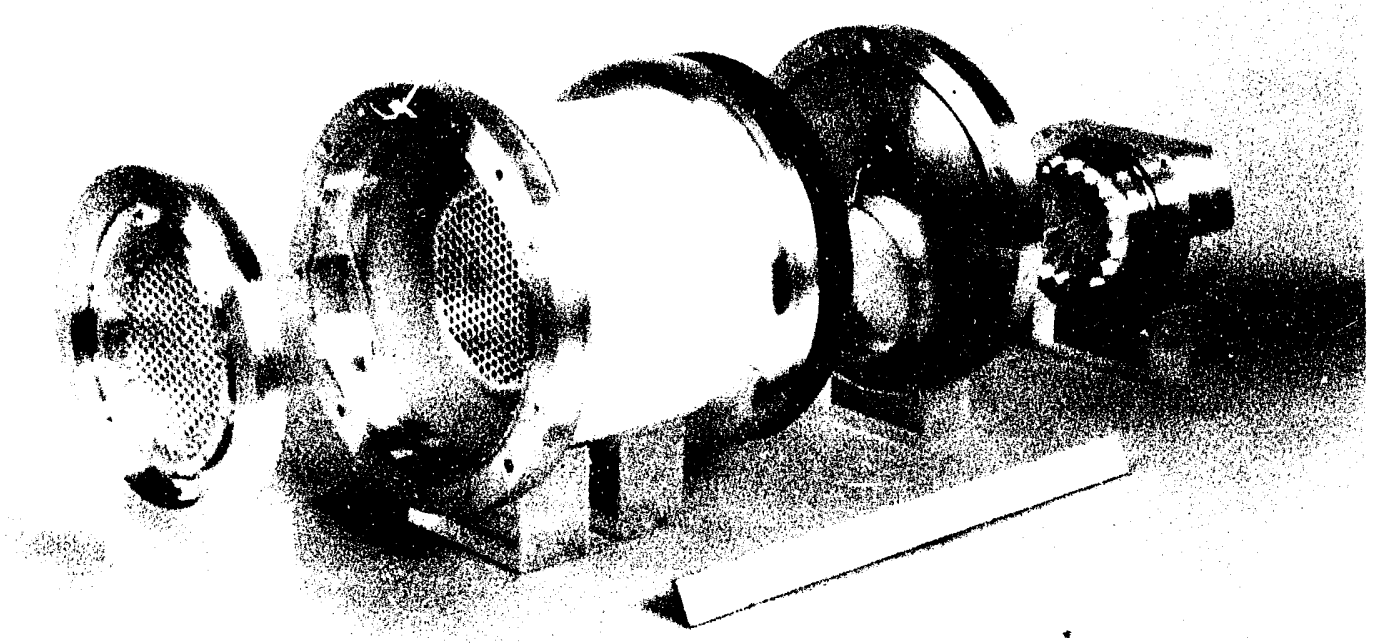

Fig. 1 The Mevva V ion source, partially disassembled to show the multiple cathode feature (holds 18 separate cathodes) and the large beam formation electrodes. (CBB 892-1124). 


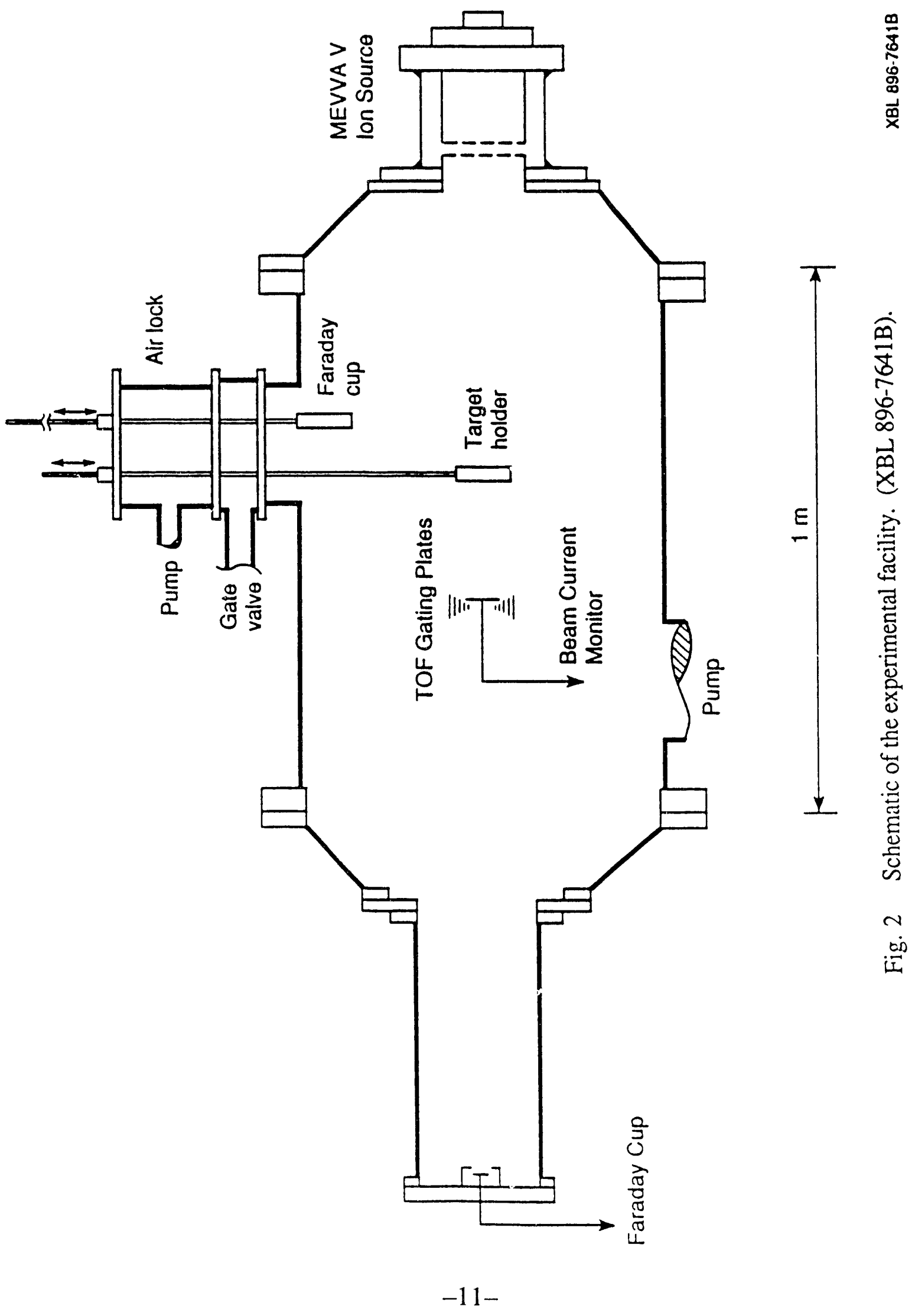




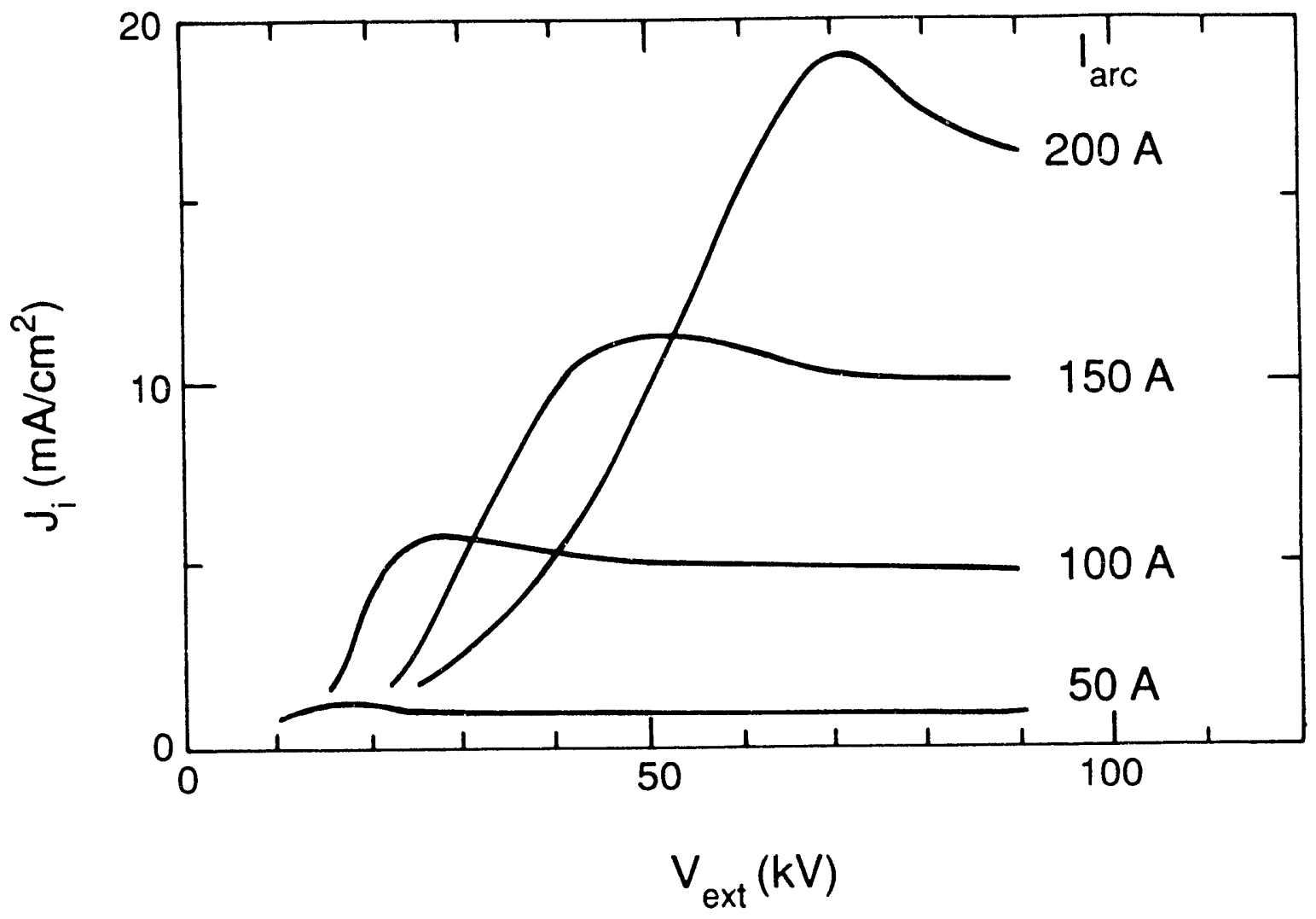

XBL $904-6340$

Fig. 3 Measured ion current density as a function of extraction voltage for several arc currents. Titanium beam. (XBL 904-6340). 


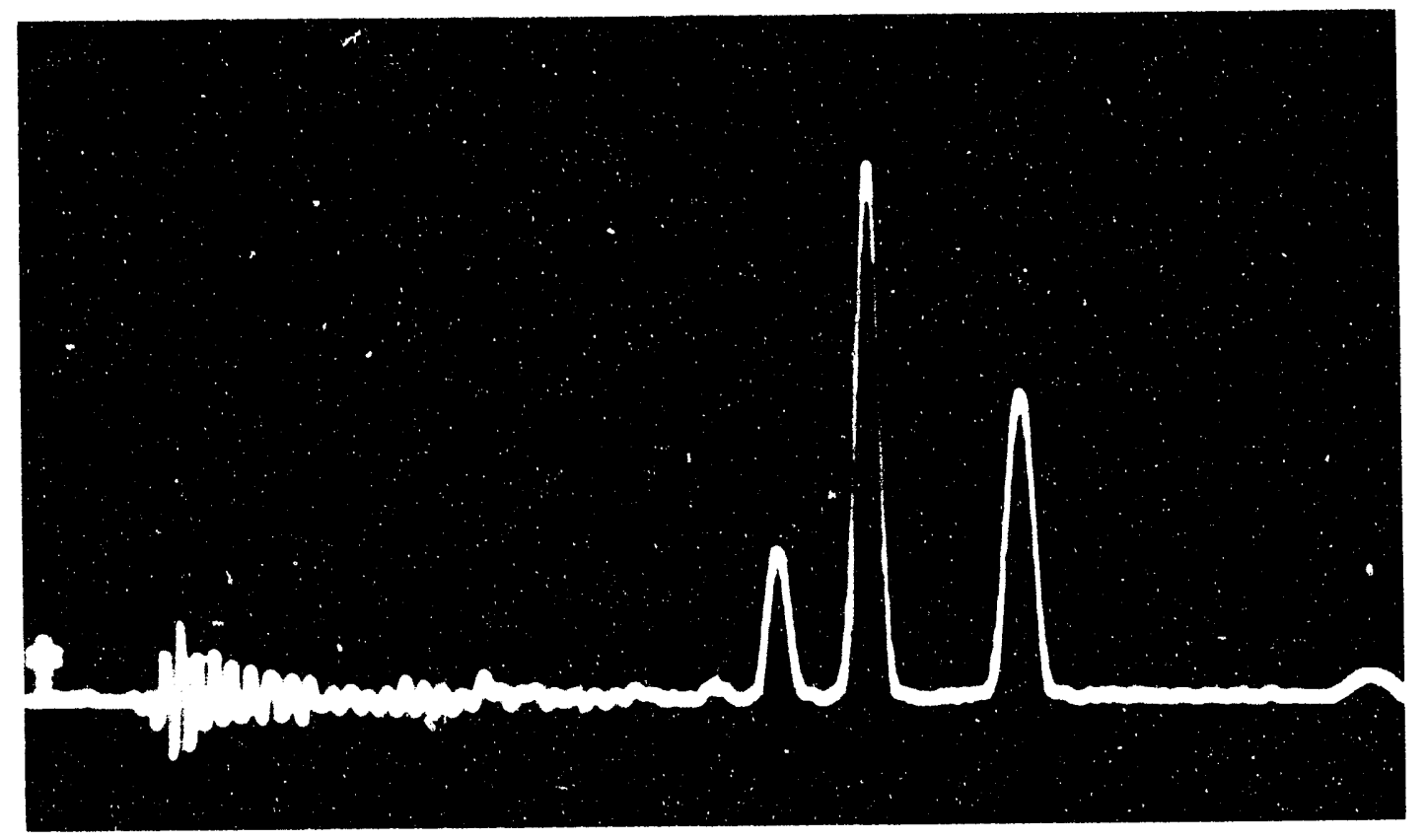

Fig. 4 Time-of-flight charge state spectrum for an iridium beam. The peaks correspond to $Q=$ $1+$ (far right), 2+, 3+ (maximum), 4+ and 5+, right to left. (XBB 907-5206). 

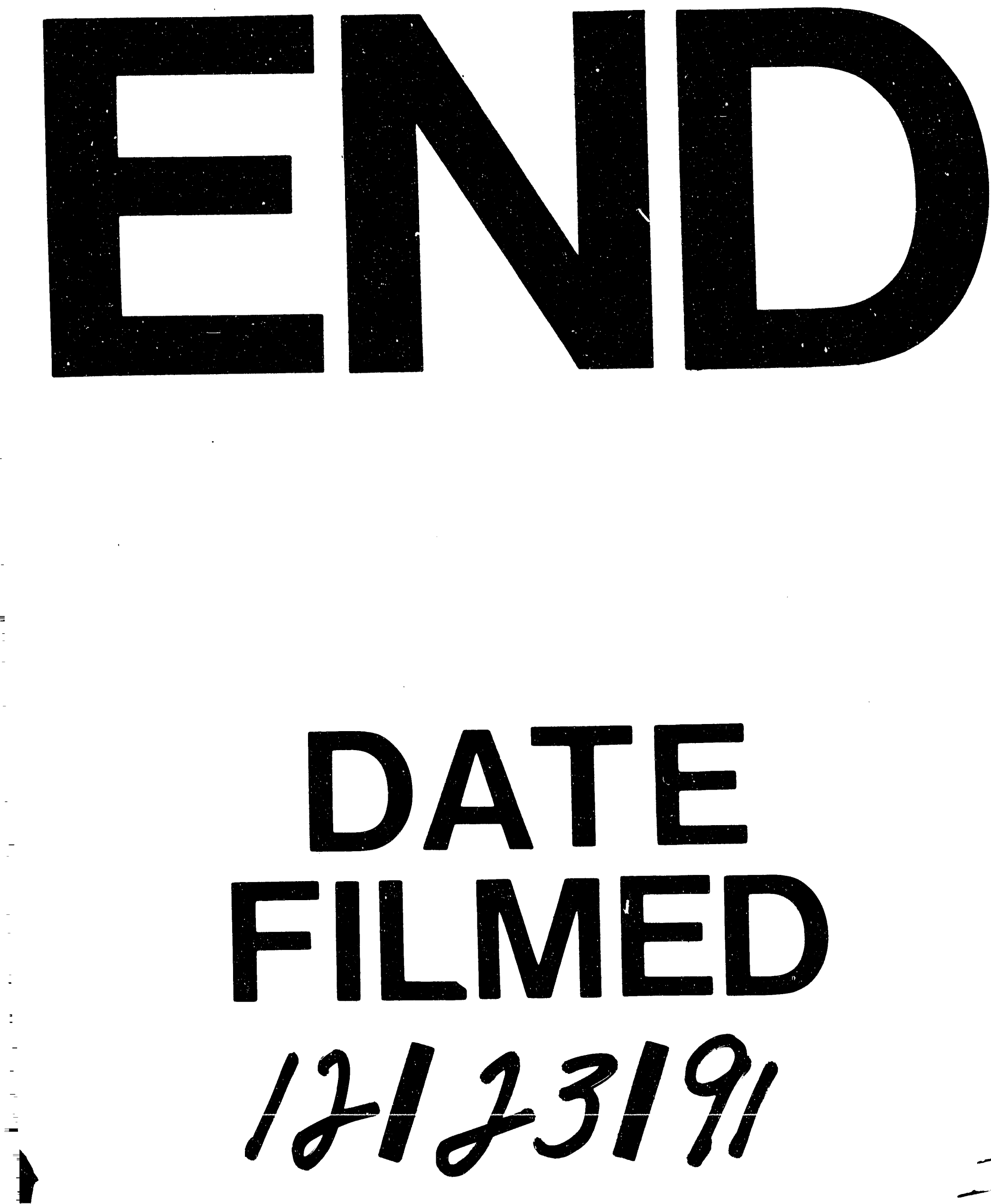
